\title{
Risk stratification for intestinal dysbiosis in hospitalized adult patients according to the National Dysbiosis Survey (INDIS)
}

\author{
Estratificação de risco para disbiose intestinal em pacientes adultos hospitalizados de acordo \\ com a Pesquisa Nacional de Disbiose (INDIS)
}

DOI: 10.37111/braspenj.2020352008

\section{Aline Okipney}

Jéssica Romanelli Amorim de Souza ${ }^{2}$

Antonio Carlos Ligocki Campos ${ }^{3}$

Leticia Fuganti Campos ${ }^{4}$

Paula Rodrigues Anjo ${ }^{5}$

Camila Abreu 6

\section{Unitermos:}

Microbioma Gastrointestinal. Disbiose. Gastroenteropatias. Inquéritos e Questionários.

\section{Keywords:}

Gastrointestinal Microbiome. Dysbiosis. Gastrointestinal diseases. Surveys and Questionnaires.

\section{Endereço de correspondência:}

Leticia Fuganti Campos

Rua Dona Alice Tibiriça, 455 - ap 701 - Curitiba, PR,

Brazil - CEP 80730-320

E-mail: le_campos@hotmail.com

\section{Submission:}

May 6, 2020

\section{Accepted for publication}

June 19,2020

\begin{abstract}
Introduction: The intestinal microbiota has a symbiotic relationship with the human being. Its alteration, known as dysbiosis, can result in several diseases. Some risk factors may predict the occurrence of this condition. The purpose of this study was to evaluate the effectiveness of the National Dysbiosis Survey (INDIS) in the risk stratification of hospitalized adult patients that presented with intestinal dysbiosis. Methods: 100 patients hospitalized at the Hospital das Clínicas da UFPR were interviewed through INDIS. In this questionnaire, risk factors for dysbiosis of each patient were established and the dysbiosis degree was stratified in low, medium, high, and very high risk. Results: Most patients were classified as medium (43\%) and high risk (39\%) of dysbiosis. The univariate analysis revealed an association between the degree of dysbiosis and elderly patients $(p=0.034)$, number of comorbidities $(p<0.001)$, presence of diarrhea or constipation $(p<0.001)$ and medication in use [antibiotic and/or proton pump inhibitor (PII); $p<0.001$ ]. In the multivariate analysis, the most important influence in classification was the presence of diarrhea or constipation $(\mathrm{OR}=3.00,95 \% \mathrm{Cl}[1.73,5.21] \mathrm{p}<0.001)$ and medication in use (Score 3: OR = $53.4,95 \% \mathrm{Cl}[2.73,1045.5], \mathrm{p}=0.009$ and Score 4-8: $\mathrm{OR}=1709.1,95 \% \mathrm{Cl}[50.27,58103.5]$ $\mathrm{p}<0.001$ ), both independent predictors of high and very high risk of dysbiosis. Conclusion: The risk degree of intestinal dysbiosis is greater in the presence of diarrhea or constipation, the use of antibiotics and/or PII, and in elderly patients. Once the risks of dysbiosis have been defined, INDIS proved to be an effective and rapid tool for risk stratification of dysbiosis in the study population, future studies should determine the relevance of therapeutic interventions with the purpose of normalizing the intestinal flora.
\end{abstract}

\section{RESUMO}

Introdução: A microbiota intestinal possui relação simbiótica com o organismo humano. A alteração desta relação, conhecida como disbiose, pode resultar em várias doenças. Alguns fatores podem predizer a ocorrência desta condição. O objetivo deste estudo foi avaliar a eficácia do Questionário Nacional de Disbiose (INDIS) na estratificação de risco em pacientes adultos hospitalizados que apresentavam disbiose intestinal. Método: O questionário INDIS foi aplicado em 100 pacientes hospitalizados no Hospital das Clínicas da UFPR. Neste questionário, os fatores de risco para disbiose em cada pacientes são estabelecidos e o grau de disbiose é estratificado em baixo, médio, alto e muito alto. Resultados: A maioria dos pacientes foi classificada como risco médio $(43 \%)$ e alto $(39 \%)$ de disbiose. A análise univariada revelou associação entre o grau de disbiose e pacientes idosos $(p=0,034)$, o número de comorbidades $(p<0,001)$, a presença de diarreia ou constipação $(p<0,001)$ e a medicação em uso (antibiótico e/ou inibidor de bomba de próton) $(p<0,001)$. Na análise multivariada, a classificação como influência mais importante foi a presença de diarreia ou constipação $(\mathrm{OR}=3.00,95 \% \mathrm{Cl}[1.73,5.21] \mathrm{p}<0,001)$ e a medicação em uso (escore 3: $\mathrm{OR}=53.4,95 \% \mathrm{Cl}[2.73,1045.5], \mathrm{p}=0009$ e escore $4-8$ : $\mathrm{OR}=1709.1,95 \%$ $\mathrm{Cl}[50.27,58103.5] \mathrm{p}<0.001)$, ambos preditores independentes do risco alto e muito alto de disbiose. Conclusões: $O$ grau de risco de disbiose é maior na presença de diarreia e constipação, no uso de antibióticos e/ou inibidor de bomba de próton e em pacientes idosos. Uma vez que os riscos de disbiose estão definidos, o INDIS provou ser uma ferramenta rápida e efetiva para determinar a disbiose na população estudada. Estudos futuros deverão determinar a relevância das intervenções terapêuticas que propõem normalizar a flora intestinal.

1. Graduated in Medicine by Universidade Federal do Paraná, Resident in Internal Medicine by Hospital Angelina Caron, Universidade Federal do Paraná, Curitiba, PR, Brazil.

2. Graduated in Medicine by Universidade Federal do Paraná, Curitiba, PR, Brazil.

3. Full Professor of the Surgery Department of the Universidade Federal do Paraná, Coordenator of the Postgraduate Program in Surgical Clinic at Universidade Federal do Paraná, Curitiba, PR, Brazil.

4. Nutritionist, Doctorate in Surgical Clinic by Postgraduate Program in Surgical Clinic at Universidade Federal do Paraná, Curitiba, PR, Brazil.

5. Nutritionist, author of the National Dysbiosis Survey (INDIS), Professor of the Postgraduate Program in Hospital Nutrition at Instituto Israelita de Ensino e Pesquisa Albert Einstein (IIEP), São Paulo, SP, Brazil.

6. Pharmaceutist by Universidade Federal do Rio de Janeiro, Master of Science by Fundação Oswaldo Cruz, author of the National Dysbiosis Survey (INDIS), Rio de Janeiro, RJ, Brasil. 


\section{INTRODUCTION}

The intestinal microbiota of each individual is unique and particular. The adult gastrointestinal tract is colonized by more than 500 species of bacteria, which differ from individual to individual, and can be compared, for some authors, to the fingerprint of each person'. This characteristic is possible due to the influence of several factors for the microbiota development, such as mode of birth, type of feeding, diet, environment, smoking, alcohol consumption, use of antibiotics and associated diseases ${ }^{2,3}$. Once the composition and number of microorganisms of the intestinal flora have been established, this habitat becomes stable and in equilibrium status with the host ${ }^{2,4}$.

The healthy intestinal microbiota is very important because of the interaction of the intestine with human health, since it is involved in stimulating the immune system, in the synthesis of vitamins (mainly group B and vitamin K) and in the stimulation of local immune responses; besides assisting in the motility and function of gastrointestinal tract by the digestion and absorption of nutrients; inhibit pathogenic bacteria by competition for intraluminal fuels, potentiate the mechanism of defenses against these agents and form a protective barrier against invading microorganisms, as well as presenting important metabolic and nutritional functions ${ }^{5,6}$.

However, some variables may interfere with this balance, making bacteria previously beneficial to humans to become pathogenic. This phenomenon is called intestinal dysbiosis. These variables include indiscriminate use of antibiotics, hormonal and non-hormonal anti-inflammatories, use of laxatives, unbalanced diet, poor digestion, excess exposure to environmental toxins as radiation, consumptive disorders, such as, cancer and AIDS, hepatopancreatic disorders, psychological and physical stress ${ }^{2,5-7}$. It is known that antibiotic therapy can harm non-pathogenic bacterial colonies, allowing pathogens to settle and occupy the mucosa causing diseases, such as Clostridium difficile infection ${ }^{8}$. In addition, in elderly, the microbiota composition is also modified compared to normal adults?. However, dysbiosis is still a clinical condition with few epidemiological data, since there is no gold standard method for its diagnosis.

In this scenario, although many relationships are still not well understood, there are a number of risk factors that lead to dysbiosis. There is already a considerable number of studies related to the change of intestinal microbiota and other intestinal or extra-intestinal diseases, such as, inflammatory intestinal diseases, irritable bowel syndrome, rheumatoid arthritis, ankylosing spondylitis, diabetes, obesity, allergies and neurological dysfunctions, which can lead to serious consequences ${ }^{1,6,7,10}$.

Thus, this study aims to verify the association of several epidemiological and clinical factors with the risk of intestinal dysbiosis in adult patients hospitalized in a large tertiary hospital, proposing a risk stratification for intestinal dysbiosis.

\section{METHODS}

One hundred adult patients hospitalized at Hospital de Clínicas da Universidade Federal do Paraná (UFPR) were randomly selected. The sample was statistically calculated so that there was an average of 10 to 15 patients per item of the questionnaire applied. The floor and bedding drawing lot was conducted through the iGerar app, prior to the interview. All patients were older than 18 years, they authorized the participation in the study and signed the Informed Consent Form.

The restricted beds were excluded from selection, such as prevention and precaution of contact, isolation and Intensive Care Unit and Coronary Unit beds. Pregnant and under 18 years old patients were also excluded from the study.

The instrument used for data collection was the National Dysbiosis Survey (INDIS) (Appendix). This instrument contains questions about the main factors that may predispose individuals to have dysbiosis, such as the age group; current clinical condition and presence of comorbidities (diabetes, systemic arterial hypertension, gastrointestinal tract diseases, neoplasms, among others); gastrointestinal symptoms and signs related to intestinal dysbiosis; use of medication that may interfere with the intestinal flora; conditions and life habits and patient mobility. In the "Conditions and life habits" variable, the items alcohol consumption, smoking and mobility have been included. Regarding alcohol consumption, they were divided into three categories: consumes frequently (from once a week), consumes eventually (less than once a week) and does not consume (less than once a year); regarding smoking, only daily consumption was considered as present. For the item mobility, they were divided into: Do not wander (restricted to bed or very reduced mobility) and wanders (self-sufficient or reduced mobility, but wanders). In order for the patient to score on the item alcohol consumption, only frequent consumption was considered. For the item smoking, ex-smokers were not considered and, finally, in the item mobility, the patients who scored were those who were bedridden and who depended on wheelchairs or third parties to be able to perform basic needs.

The questions were divided into 8 topics, with a maximum score on each topic according to the response of the interviewed patient. At the end, the points were added and the risk degree of dysbiosis was determined. According to the score, the patients were classified into four strata of risk for dysbiosis: low risk (0 to 4 points), medium risk (5 to 10 points), high risk ( 11 to 16 points) and very high risk ( 17 to 22 points).

INDIS is an instrument originally developed by the FQM Farmoquimica group and adapted by the authors, whose content of the questions is based on scientific evidence of conditions that predispose individuals to a greater or lesser risk of developing dysbiosis. The questionnaire was applied by the authors, who were previously trained, and the mean time of application per patient was about 10 minutes. Information, mainly regarding medication and comorbidities, was complemented by consultation after the patients' medical records.

The research was submitted and approved by the Research Ethics Committee on Human Beings of HC-UFPR (CAAE: 47198715.1.0000.0096).

\section{Statistical Analysis}

Descriptive statistics were expressed as mean, standard deviation (SD) and minimum and maximum. Frequency and 
percentage were used for categorical or qualitative variables. The data were analyzed for homogeneity and Chi square tests (for qualitative variables) and ANOVA (analysis of variance) tests were used to compare means (for quantitative variables). The Pearson or Spearman correlation coefficient was calculated for the drug use variable in relation to the outcome (final questionnaire score).

The multiple linear regression method was used to study the linear association between each of the items with the value of the final survey score. Thus, it was possible to create or establish a multiple linear regression model in order to predict the value of the relevant variables in the study.

The multivariate binary logistic regression method was performed to predict the stratification of the dysbiosis risk (low-moderate risk of dysbiosis) or high-very high risk of dysbiosis according to the main relevant variables and risk factors group. With this, it was possible to establish a weighting of these risk factors, that is, to know which of the items in the form is associated with a greater probability of having intestinal dysbiosis.

To evaluate the internal consistency of the INDIS form, the statistical method of Alpha Cronbach was performed.

Epidemiological measures have been established using 95\% confidence intervals to estimate the prevalence (percentages) of risk factors for dysbiosis and, also, the risk before odds ratio for dysbiosis has been determined.

The significance level of $5 \%(a=0.05)$ was used, i.e., results of statistical tests with descriptive levels ( $p$ values) of less than 5\% have been considered significant. Statistical tests were bilateral. All the analyses were performed through the IBM SPSS Statistics, version 22 program.

\section{RESULTS}

We studied 100 patients, 58 females and 42 males, whose mean age was 51.6 years with a standard deviation of 17.1 years, minimum 18 years old and maximum 86 years old (Table 1).

The total scores for the dysbiosis degree (sum of the items from the INDIS questionnaire) have an average of 10 points and a standard deviation of 4.25 points (minimum of 2 and maximum of 20), with a $p=0.067$ for Kolmogorov-Smirnov test, which reflects the normality of distribution. Regarding risk stratification for dysbiosis according to the four degrees arbitrarily established according to the results of the sum of scores, a frequency of $9 \%$ was found for low risk $(0$ to 4 points) and $9 \%$ for a very high risk of dysbiosis ( 17 to 22 points). The other patients were classified as $43 \%$ for medium risk of dysbiosis and 39\% for high risk of dysbiosis (Table 2 and Figure 1).

The distribution of total scores to INDIS questionnaire in a global and discriminated manner according to the patient's gender did not show a significant difference for this last analysis $(p=0.641)$ (Table 3$)$. There is no evidence that the dysbiosis degree is related to the patient's gender $(p=0.807)$.

\section{Univariate Analysis of the Dysbiosis Risk Degree}

The dysbiosis risk degree was assessed through the sum of scores of the INDIS questionnaire and its possible association with the scores of each item of the questionnaire. The results described showed that there is a statistically significant association between the dysbiosis degree and some of the items in the questionnaire: age, clinical condition, gastrointestinal symptoms (constipation) and medications (Table 4). In conclusion, in addition to the association using Kendall's Tau-B and Kendall's Tau-C statistic, the higher the score in these items, the greater the dysbiosis degree (Kendall's Tau values: $0.223,0.301,0.532$ and 0.605 respectively for the variables studied). According to the arbitrary scale of Kendall's

Table 1 - Main socio-demographic characteristics in studied patients through questionnaire INDIS $2015(n=100)$.

\begin{tabular}{lccc}
\hline \multicolumn{1}{c}{$\mathbf{N}=\mathbf{1 0 0}$} & Male (n=42) & Female (n=58) & P-value \\
\hline Age per gender (years) & $54(16.2) ;$ & $50(17.7) ;$ & 0.247 \\
Mean (Standard Deviation); & $20-86$ & $18-85$ & \\
minimum - maximum & & & \\
\hline $\begin{array}{l}\text { Overall age }{ }^{\star} \text { (years) } \\
\text { Mean (Standard Deviation); }\end{array}$ & $51.6(17.1) ;$ & $-18-86$ & \\
minimum - maximum & & \\
\hline
\end{tabular}

* Non-significant Kolmogorov-Smirnov / Shapiro-Wilk test ( $p>0.05$ for all studied variables).

Table 2 - Risk stratification for dysbiosis from results of studied patients through questionnaire INDIS $2015(n=100)$.

\begin{tabular}{lc}
\hline \multicolumn{1}{c}{ Degree of dysbiosis } & Absolute frequency (\%) \\
\hline 1. Low dysbiosis risk $(0 \leq$ Score $\leq 4)$ & $9(9 \%)$ \\
2. Medium dysbiosis risks $(5 \leq$ Score $\leq 10)$ & $44(44 \%)$ \\
3. High dysbiosis risk $(11 \leq$ Score $\leq 16)$ & $38(38 \%)$ \\
4. Very high dysbiosis risk $(17 \leq$ Score $\leq 22)$ & $9(9 \%)$ \\
\hline
\end{tabular}

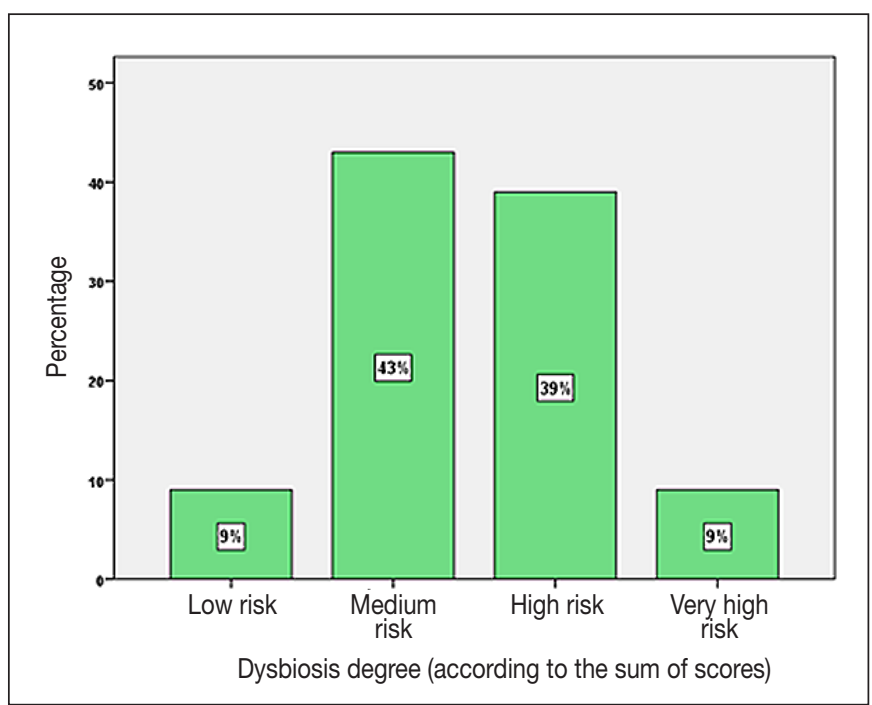

Figure 1 - Distribution of the percentage relative frequency of different dysbiosis degrees through the sum of scores in the studied patients, according to questionnaire INDIS $2015(n=100)$. 
Table 3 - Distribution of the main variables in the studied patients through questionnaire INDIS $2015(n=100)$ according to patient's sex.

\begin{tabular}{|c|c|c|c|}
\hline$N=100$ & Male $(n=42)$ & Female $(n=58)$ & P-value \\
\hline $\begin{array}{l}\text { Total score in INDIS } 2015 \xi / \varphi \\
\text { Mean (Standard Deviation); Minimum - maximum }\end{array}$ & $\begin{array}{l}10.21(4.36) ; \\
2-18\end{array}$ & $\begin{array}{l}9.81(4.19) \\
\quad 2-20\end{array}$ & $0.641 \psi$ \\
\hline $\begin{array}{l}\text { Overall total score in INDIS } 2015 \xi \\
\text { Mean (Standard Deviation); Minimum - maximum }\end{array}$ & \multicolumn{2}{|c|}{$\begin{array}{l}9.98(4.25) \\
2-20\end{array}$} & 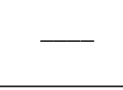 \\
\hline Degree of dysbiosis & Male $(n=42)$ & Female $(n=58)$ & P-value \\
\hline 1. Low risk of dysbiosis $(0 \leq$ Score $\leq 4)$ & $3(7.1 \%)$ & $6(10.3 \%)$ & \\
\hline 2. Medium risk of dysbiosis $(5 \leq$ Score $\leq 10)$ & $18(42.9 \%)$ & $26(44.8 \%)$ & $0.807 \mathrm{~s}$ \\
\hline 3. High risk of dysbiosis ( $11 \leq$ Score $\leq 16)$ & $16(38.1 \%)$ & $22(37.9 \%)$ & \\
\hline 4. Very high risk of dysbiosis ( $17 \leq$ Score $\leq 22$ ) & $5(11.9 \%)$ & $4(6.9 \%)$ & \\
\hline
\end{tabular}

$\xi$ Non-significant Kolmogorov-Smirnov / Shapiro-Wilk test ( $p>0.05) ; \varphi$ Non-significant Levene's test for equality of variances ( $p>0.05) ; \psi \psi$ Student test for independent samples; $\varsigma$ Chi Square test.

Table 4 - Distribution of the main variables in the studied patients through questionnaire INDIS $2015(n=100)$, according to patient's degree of dysbiosis.

\begin{tabular}{|c|c|c|c|c|c|}
\hline Degree of dysbiosis & $\begin{array}{c}\text { Low risk of dys- } \\
\text { biosis } \\
(0 \leq \text { Score } \leq 4) \\
N=9\end{array}$ & $\begin{array}{c}\text { Medium risk of } \\
\text { dysbiosis } \\
(5 \leq \text { Score } \leq 10) \\
N=44\end{array}$ & $\begin{array}{c}\text { High risk of dys- } \\
\text { biosis } \\
\begin{array}{c}(11 \leq \text { Score } \leq 16) \\
N=38\end{array}\end{array}$ & $\begin{array}{c}\text { Very high risk of } \\
\text { dysbiosis } \\
\text { (17 } \leq \text { Score } \leq 22) \\
\mathrm{N}=9\end{array}$ & $P$ value \\
\hline \multicolumn{6}{|l|}{ 1. Age range } \\
\hline Score 0 & $9(100 \%)$ & $27(61.4 \%)$ & $21(55.3 \%)$ & $4(44.4 \%)$ & $0.062 \varphi$ \\
\hline Score 1 & $\overline{-}$ & $17(38.6 \%)$ & $17(44.7 \%)$ & $5(55.6 \%)$ & $0.023 \psi$ \\
\hline \multicolumn{6}{|l|}{ 2. Clinical condition } \\
\hline Score 0 & - & $5(11.4 \%)$ & $1(2.6 \%)$ & - & \\
\hline Score 1-3 & $7(77.8 \%)$ & $22(50 \%)$ & $12(31.6 \%)$ & $1(11.1 \%)$ & $0.009 \varphi$ \\
\hline Score 4 & $2(22.2 \%)$ & $17(38.6 \%)$ & $25(65.8 \%)$ & $8(88.9 \%)$ & $<0.001 \psi$ \\
\hline \multicolumn{6}{|l|}{ 3. Current treatment } \\
\hline Score 0 & $5(55.6 \%)$ & $19(43.2 \%)$ & $23(60.5 \%)$ & $2(22.2 \%)$ & $0.148 \varphi$ \\
\hline Score 1 & $4(44.4 \%)$ & $25(56.8 \%)$ & $16(39.5 \%)$ & $7(77.8 \%)$ & $0.950 \Psi$ \\
\hline \multicolumn{6}{|l|}{ 4. Gastrointestinal symptoms } \\
\hline \multicolumn{6}{|l|}{ 4.a Diarrhea } \\
\hline Score 0 & $9(100 \%)$ & $43(97.7 \%)$ & $34(89.5 \%)$ & $8(88.9 \%)$ & $0.327 \varphi$ \\
\hline Score 5 & - & $1(2.3 \%)$ & $4(10.5 \%)$ & $1(11.1 \%)$ & $0.068 \psi$ \\
\hline \multicolumn{6}{|l|}{ 4.b Constipation } \\
\hline Score 0 & $9(100 \%)$ & $39(88.6 \%)$ & $20(52.6 \%)$ & $1(11.1 \%)$ & $<0.001 \varphi$ \\
\hline Score 5 & - & $5(11.4 \%)$ & $18(47.4 \%)$ & $8(88.9 \%)$ & $<0.001 \psi$ \\
\hline \multicolumn{6}{|l|}{ 5. Medications } \\
\hline Score 0 & $9(100 \%)$ & $10(22.7 \%)$ & $1(2.6 \%)$ & - & \\
\hline Score 1 & - & $1(2.3 \%)$ & $1(2.6 \%)$ & - & $<0.001 \varphi$ \\
\hline Score 3 & - & $22(50 \%)$ & $9(23.7 \%)$ & - & $<0.001 \psi$ \\
\hline Score 4-8 & 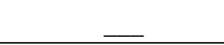 & $11(25 \%)$ & $27(71.1 \%)$ & $9(100 \%)$ & \\
\hline \multicolumn{6}{|l|}{ 6. Smoking } \\
\hline Score 0 & $9(100 \%)$ & $36(81.8 \%)$ & $29(76.3 \%)$ & $6(66.7 \%)$ & $0.300 \varphi$ \\
\hline Score 1 & $\ldots$ & $8(18.2 \%)$ & $9(23.7 \%)$ & $3(33.3 \%)$ & $0.073 \psi$ \\
\hline \multicolumn{6}{|l|}{ 7. Alcohol consumption } \\
\hline Score 0 & $8(88.9 \%)$ & $40(90.9 \%)$ & $35(92.1 \%)$ & $8(88.9 \%)$ & $0.984 \varphi$ \\
\hline Score 1 & $1(11.1 \%)$ & $4(9.1 \%)$ & $3(7.9 \%)$ & $1(11.1 \%)$ & $0.900 \psi$ \\
\hline \multicolumn{6}{|l|}{ 8. Mobility } \\
\hline Score 0 & $8(88.9 \%)$ & $40(90.9 \%)$ & $34(89.5 \%)$ & $7(77.8 \%)$ & $0.722 \varphi$ \\
\hline Score 1 & $1(11.1 \%)$ & $4(9.1 \%)$ & $4(10.5 \%)$ & $2(22.2 \%)$ & $0.528 \psi$ \\
\hline
\end{tabular}

$\varphi$ Chi Square Test; $\xi$ Kendall Tau-B Test; $\psi$ Kendall Tau-C Test. 
ordinal correlation, it indicates that for the variables age range and clinical condition, there is a low correlation, however, for the variables: gastrointestinal symptoms (constipation) and medications, the correlation is average and good respectively.

The same variables from the INDIS questionnaire have also been evaluated in relation to the dysbiosis degree in binary form, i.e., in two categories: low and medium dysbiosis risk (scores between 0 and 10 points) or high and very high dysbiosis risk (scores between 11 and 22 points). It was found that the variables significantly associated with the dysbiosis degree were: clinical condition (Kendall's Tau-C $=0.357$ ),

Table 5 - Distribution of the main variables in the studied patients through questionnaire INDIS 2015 ( $n=100$ ) according to patient's degree of dysbiosis; low and medium risk of dysbiosis (scores between 0 and 10 points) or high and very high risk of dysbiosis (scores between 11 and 22 points).

\begin{tabular}{lccc}
\hline Degree of dysbiosis & $\begin{array}{c}\text { Low and medium } \\
\text { risk of dysbiosis } \\
(\mathbf{0} \leq \text { Score } \leq 10) \\
\mathbf{N}=53\end{array}$ & $\begin{array}{c}\text { High and very high } \\
\text { risk of dysbiosis } \\
(11 \leq \text { Score } \leq 22) \\
\mathbf{N}=47\end{array}$ & P value \\
\hline 1. Age range & & & \\
Score 0 & $36(67.9 \%)$ & $25(53.2 \%)$ & $0.132 \varphi$ \\
Score 1 & $17(32.1 \%)$ & $22(46.8 \%)$ & $0.175 \xi$ \\
\hline 2. Clinical condition & $5(9.4 \%)$ & $1(2.1 \%)$ & $0.002 \varphi$ \\
Score 0 & $29(54.7 \%)$ & $13(27.7 \%)$ & $<0.001 \Psi$ \\
Score 1-3 & $19(35.8 \%)$ & $33(70.2 \%)$ & \\
Score 4 & & & \\
\hline 3. Current treatment & $24(45.3 \%)$ & $25(53.2 \%)$ & $0.430 \varphi$ \\
Score 0 & $29(54.7 \%)$ & $22(46.8 \%)$ & $0.428 \xi$ \\
Score 1 & & &
\end{tabular}

\begin{tabular}{lccc}
\hline $\begin{array}{l}\text { 4. Gastrointestinal } \\
\text { symptoms }\end{array}$ & & & \\
4.a Diarrhea & & & \\
$\quad$ Score 0 & $52(98.1 \%)$ & $42(89.4 \%)$ & $0.077 \varphi$ \\
Score 5 & $1(1.9 \%)$ & $5(10.6 \%)$ & $0.072 \xi$ \\
4.b Constipation & & & \\
$\quad$ Score 0 & $48(90.6 \%)$ & $21(44.7 \%)$ & $<0.001 \varphi$ \\
$\quad$ Score 5 & $5(9.4 \%)$ & $26(53.6 \%)$ & $<0.001 \xi$ \\
\hline 5. Medications & & & \\
Score 0 & $19(35.8 \%)$ & $1(2.1 \%)$ & \\
Score 1 & $1(1.9 \%)$ & $1(2.1 \%)$ & $<0.001 \varphi$ \\
Score 3 & $22(41.5 \%)$ & $9(19.1 \%)$ & $<0.001 \psi$ \\
Score 4-8 & $11(20.8 \%)$ & $36(76.6 \%)$ & \\
\hline 6. Smoking & & & \\
Score 0 & $45(84.9 \%)$ & $35(74.5 \%)$ & $0.193 \varphi$ \\
Score 1 & $8(15.1 \%)$ & $12(25.5 \%)$ & $0.194 \xi$ \\
\hline 7. Alcohol & & &
\end{tabular}

\section{Alcohol} consumption

\begin{tabular}{cccc} 
Score 0 & $48(90.6 \%)$ & $43(91.5 \%)$ & $0.577 \varphi$ \\
Score 1 & $5(9.4 \%)$ & $4(8.5 \%)$ & $0.872 \xi$ \\
\hline 8. Mobility & & & \\
Score 0 & $48(90.6 \%)$ & $41(87.2 \%)$ & $0.595 \varphi$ \\
Score 1 & $5(9.4 \%)$ & $6(12.8 \%)$ & $0.597 \xi$ \\
\hline
\end{tabular}

$\varphi$ Chi Square Test; $\xi$ Kendall Tau-B Test; $\psi$ Kendall Tau-C Test. gastrointestinal symptoms "constipation" (Kendall's Tau-B = 0.457) and medications (Kendall's Tau- 0.618), so that there is a low, moderate and good ordinal correlation between the dysbiosis degree and the variables, respectively (Table 5).

Otherwise, it was studied whether the scores of the different items from the INDIS questionnaire were related to the dysbiosis degree, using Student's t-tests and ANOVA (analysis of variance), finding a significant difference in means of the scores of dysbiosis degree in the variables: age group, clinical condition, gastrointestinal symptoms and medications (Table 6).

Table 6 - Description of the main variables in the studied patients through questionnaire INDIS 2015 ( $n=100)$ according to study item.

\begin{tabular}{lcc}
\hline $\begin{array}{c}\text { Questionnaire INDIS 2015 } \\
\text { Item }\end{array}$ & $\begin{array}{c}\text { Mean } \\
\text { (Standard Deviation) }\end{array}$ & P value \\
\hline $\begin{array}{l}\text { 1. Age range } \\
\text { Score 0 }(n=61)\end{array}$ & $9.0(4.2)$ & $0.005 \Psi$ \\
Score 1 $(n=39)$ & $11.5(3.9)$ & \\
\hline 2. Clinical condition & & $<0.001 \varphi$ \\
Score 0 $(n=6)$ & $8.0(3.3)$ & \\
Score 1-3 $(n=42)$ & $8.0(3.6)$ & \\
Score 4 $(n=52)$ & $11.9(4.1)$ & $0.672 \Psi$ \\
\hline 3. Current treatment & & \\
Score 0 $(n=49)$ & $9.8(3.7)$ & \\
Score 1 $(n=51)$ & $10.2(4.7)$ &
\end{tabular}

\section{Gastrointestinal} symptoms

4a. Diarrhea

$\begin{array}{lcc}\text { Score } 0(n=94) & 9.9(4.3) & 0.231 \Psi \\ \text { Score } 5(n=6) & 12.0(3.4) & \end{array}$

4b. Constipation

Score $0(n=69) \quad 8.0(3.3) \quad<0.001 \Psi$

Score $5(n=31) \quad 14.0(3.2)$

\section{Medications}

Score $0(n=20) \quad 5.6(2.9)$

Score $1(n=2) \quad 8.0(4.2) \quad<0.001 \varphi$

Score $3(n=31) \quad 8.9(2.7)$

Score 4-8 $(n=47) \quad 12.6(3.7)$

\section{Smoking}

\begin{tabular}{lcc} 
Score $0(n=80)$ & $9.7(4.2)$ & $0.152 \Psi$ \\
Score $1(n=20)$ & $11.2(4.1)$ & \\
\hline
\end{tabular}

\section{Alcohol consumption}

Score $0(n=91)$

$10(4.2)$

$0.947 \Psi$

Score $1(n=9)$

$9.9(5.4)$

\section{Mobility}

Score $0(n=89)$

$9.8(4.1)$

$0.322 \psi$

Score $1(n=11)$

$11.2(5.2)$

$\psi$ Student $t$ test for comparison of independent samples; $\varphi$ ANOVA test. 
The correlation between the medication score and the INDIS score was studied using the Spearman Rho coefficient, with a moderate positive and significant correlation (Rho $=0.645 ; p<0.001$ ), which reflects that as the medication score increases, the dysbiosis degree increases in the same direction and significantly.

\section{Multivariate Analysis Using Linear Regression and Logistic Models}

The variables composing the INDIS questionnaire have been evaluated using the binary logistic regression model in a multivariate form (Table 7). The variables influencing the overall score and with more weight are only the gastrointestinal symptoms (constipation) (odds ratio $=1.95,95 \% \mathrm{Cl}$ $[1.39,2.74] p<0.001)$ and the medication that the patient receives, where "Dummy" variables have been created, considering as reference category (that category that will be compared against each of the other categories) patients with score 4-8, where the comparisons with scores 0 and 3 were statistically significant, where the latter behave as possible protection factors of dysbiosis (score 0: odds ratio $=0.01$, $95 \% \mathrm{Cl}[0.00 ; 0.08] \mathrm{p}<0.001$ and score 3 : odds ratio $=0.10$, $95 \% \mathrm{Cl}[0.03 ; 03.5] \mathrm{p}<0.001$ ) (Table 7).

It should be noted that the range of confidence intervals is very large, or little precise, probably due to the low sample size in each of the groups. It is interpreted that as the value of both (patient constipation or receiving medication) scores increases, the likelihood of high and very high risk of dysbiosis increases independently.

In other words, these two variables are independent predictors of high and very high risk of dysbiosis, i.e., high values of the scores for these two variables increase the chances of high and very high risk of dysbiosis, one variable independently of the other one (also called: adjusted odds ratio values).

In order to predict the value of the dysbiosis degree (INDIS total score) through each of the questionnaire items, the multiple linear regression model was used (Table 8). Through this model, we find that the variables that can significantly predict $\left(\mathrm{F}_{95}{ }^{4}=152.227 ; \mathrm{p}<0.001\right)$ the overall score of the INDIS questionnaire for the dysbiosis degree are: age group, patient's clinical condition, gastrointestinal symptoms and medication received.

In this way, we can affirm that in statistically significant terms, the higher the value of the score for each questionnaire item, the higher the estimated value of the overall INDIS score, i.e., greater the estimated dysbiosis risk (since the coefficient " $b$ " or regression coefficient is positive for all variables).

\section{Analysis of Internal Consistency}

The internal consistency measure from the INDIS

Table 7 - Multivariate analysis through binary logistic regression of the main variables of the studied patients through questionnaire INDIS 2015 ( $\mathrm{n}=100$ ), according to the patient's high and very high risk of dysbiosis.

\begin{tabular}{lccccc}
\hline \multicolumn{1}{c}{ Variable } & B & Standard error & OR & $95 \% \mathrm{Cl}_{\text {OR }}$ & P-value \\
\hline $\begin{array}{l}\text { Constant } \\
\begin{array}{l}\text { Gastrointestinal symptoms: } \\
\text { constipation }\end{array}\end{array}$ & 0.496 & 0.38 & - & - & $<0.001$ \\
$\begin{array}{l}\text { Patient's medication } \\
\text { Score 4-8 (reference) }\end{array}$ & 0.667 & 0.174 & 1.95 & $1.39-2.74$ & $<0.001$ \\
Score 0 & - & - & 1 & - & - \\
Score 1 & -5.14 & 1.34 & 0.01 & $0.01-0.08$ & $<0.001$ \\
Score 3 & -2.16 & 2.01 & 0.12 & $0.02-5.89$ & 0.281 \\
\hline
\end{tabular}

* Non-significant Hosmer-Lemeshow test $(\mathrm{p}=0.056)$

Table 8 - Multivariate analysis through multiple linear regression of the main variables of the studied patients through questionnaire INDIS $(n=100)$.

\begin{tabular}{lccccc}
\hline \multicolumn{1}{c}{ Variable } & B & Standard error & t Student & 95\% Cl & P-value \\
\hline Constant & 0.33 & 0.53 & 0.62 & $-0.72-1.37$ & 0.534 \\
Age range & 0.78 & 0.35 & 2.23 & $0.09-1.47$ & 0.028 \\
Patient's clinical condition & 2.12 & 0.29 & 7.39 & $1.55-2.69$ & $0.80-1.07$ \\
Gastrointestinal symptoms & 0.94 & 0.07 & 2.23 & $1.39-1.81$ & $<0.001$ \\
Patient's medication & 1.60 & 0.11 & 15.08 & $<0.001$ & 1 \\
\hline
\end{tabular}


questionnaire can be measured using the Cronbach alpha index. Given that this is an element to study, it is an instrument of reliability (that is, if the questionnaire is a reliable instrument to measure dysbiosis risk). Using in the internal consistency analysis, we found that the Cronbach's alpha index value is equal to 0.154 , which shows a low internal consistency. This may be due to the fact that some of the variables under study have a negative correlation coefficient (for example, age group with current treatment, smoking and alcohol consumption).

With a larger number of subjects, it could be possible to increase the power of the study to find other expected differences in the questionnaire, including the value of Cronbach's alpha index.

The internal consistency is affected since some items from the questionnaire simply have two categories, in the case of having more than two levels, it would be much more needed to be able to study the correlation between the variables.

Some variables have co-linearity, which means they may be confounding variables, for example: the existence of gastrointestinal symptoms may be correlated with the fact of a certain clinical condition and this leads to receiving certain medication. In this way, the overall value to measure the dysbiosis risk may not be the three variables but only one, for example clinical condition (or drug treatment received).

\section{DISCUSSION}

The main findings of this research reveal a strong association of intestinal dysbiosis with gastrointestinal symptoms diarrhea and/or constipation, use of antibiotics and/or gastric protectors, number of comorbidities and age group (above 60 years old). Regarding the first two variables, it is interpreted that, insofar as the score of medication or gastrointestinal symptoms increases, the dysbiosis degree increases in the same direction and in a significant way, with probability of presenting high and very high dysbiosis risk. These observations are in line with numerous studies that show the correlation of these events with changes in the intestinal flora ${ }^{5,6,11}$. Patients with more than 4 points in the item - medications in use - had approximately 1700 times more likely to be at high and very high dysbiosis risk. This is due to the fact that most patients that were included in this score were in antibiotic use, except for four patients who scored 4 for the item because of the use of gastric protector ( 3 points) and laxative (1 point), totaling 4 points. This strong interaction of antibiotics and change in intestinal flora has been demonstrated in several studies. Pérez-Cobas et al. ${ }^{12}$ demonstrated specific properties of antibiotics, such as a mode of action and antimicrobial effects that can make selection of the intestinal microbiota, besides selecting resistant genes, favoring growth of pathogenic organisms and altering the balance and the symbiosis relation of the intestinal flora.
Intestinal dysbiosis is responsible for a variety of GI diseases, which have already been described in the literature. It is known that chronic inflammatory bowel diseases, irritable bowel syndrome and antibiotic-associated diarrhea are conditions that combine intestinal microbiota imbalance and diarrhea ${ }^{13}$.

In the study by Gorkiewicz et al. ${ }^{13}$, osmotic diarrhea was induced in four individuals previously healthy through the administration of polyethylene glycol (PEG). Mucosal and feces samples from these individuals have been collected before, during and after diarrhea and analyzed by PCR method, which identified the effect of diarrhea on intestinal microbiota change. Diarrhea led to a significant decrease in the variety of phyla in the feces $(p=0.0295)$ and there was a prominent displacement of communities of mucosal bacteria obtained before and during diarrhea $(p=0.0044)$. The authors concluded that, even in healthy subjects, diarrhea alters the intestinal flora.

The symptom of constipation is observed mainly in individuals' adherents of the so-called western diet, which contains low fiber intake. Modern lifestyle and inadequate diet has led to changes in the intestinal microbiota ${ }^{14}$. Western diet favors significantly reduced microbiota formation compared to our ancestors and individuals living in the rural environment. The explanation is due to the fact that most of the nutrients' absorption from the western diet occurs in the proximal portion of the small intestine. Therefore, the substrates necessary for the subsistence of the microbiota do not reach the colon ${ }^{15}$.

In this study, gastrointestinal symptoms were positively correlated with the dysbiosis risk. All patients at very high risk for dysbiosis had diarrhea or constipation, and it was shown that these symptoms increase by three times the chance of being at high or very high dysbiosis risk.

Relating dysbiosis to the age group, more than $50 \%$ of patients over 60 years old were at very high risk for dysbiosis, a fact that can be explained due to the nutrition, often insufficient for the elderly's demand. In the study by DudaChodak et al. ${ }^{9}$, it was evident that changes in eating habits due to morbidities that require greater food restrictions are responsible for changing the microbiota of these patients. In addition, age-specific physiological changes require a differentiated and supplemented diet and, in this way, a vicious cycle is established. The differentiated diet leads to dysbiosis, which generates pathological processes that affect the nutritional status of elderly, also increasing their susceptibility to infectious processes ${ }^{11}$.

When harmful bacteria proliferate exaggeratedly in the small intestine, they have serious consequences for the host as a whole and not only in the gastrointestinal tract. Parallel to the increase of pathogens, there is an increase in the permeability 
or breakage of the intestinal barrier, with microflora imbalance, which may even be a predisposing factor for autoimmune, cardiovascular, neurological and cancerous diseases ${ }^{15,16}$.

With this, it is evidenced that the patient's clinical condition or its comorbidities are related to intestinal dysbiosis. It is accepted that Clostridium difficile infection is often due to intestinal dysbiosis. However, the evidence shows that dysbiosis is also associated with several intestinal inflammatory bowel diseases and also extra-intestinal diseases, which has been the relevant subject of research to determine its relation with intestinal microbiota changes. The number and composition of Bifidobacteria, for example, are commonly altered in these conditions ${ }^{17}$.

The study by Lankelma et al. ${ }^{4}$ demonstrated the role of the intestinal microbiota in intestinal infections, inflammatory bowel disease, colorectal cancer and even allergies and airway infections, as an example of extra-intestinal diseases.

In the results obtained by the application of INDIS, 68.8\% of patients with high or very high dysbiosis risk had four or more clinical comorbidities. That is, the presence of several diseases increased significantly the dysbiosis risk. However, this variable has co-linearity with other variables. The existence of a certain clinical condition may be correlated with gastrointestinal symptoms or the use of certain medications.

It was evaluated whether the type of treatment, clinical or surgical, influenced the result. Patients with a score equal to 1 were those submitted to surgical procedures, equivalent to $51 \%$ of the interviewees, and there was no difference in the dysbiosis degree between the clinical and surgical patients. The hypothesis that surgical treatment could influence the dysbiosis degree is due to the greater psychological or physical stress to which the patient is subjected.According to Daian et al. ${ }^{8}$, there are internal and external sources of stress, with physical, emotional, behavioral and hormonal components that contribute to the existence of perioperative stress.

Stress-induced changes in GI microbiota may be caused by the effect of elevated levels of catecholamines, especially norepinephrine, that are characteristic of surgical patients. These effects are increased proliferation of potentially pathogenic microorganisms and changes in gastrointestinal motility and secretion ${ }^{6}$. However, in this study, the dysbiosis risk was similar in clinical and surgical patients, raising the hypothesis that this stress may not be higher in the surgical patient than the stress of the hospitalization itself that patients undergoing clinical treatment are submitted. Other factors should be considered, such as the length of hospitalization, the disease severity, and the way each patient handles their illness.

Regarding the conditions and life habits, the frequent alcohol consumption did not present a statistically significant relation with the dysbiosis risk, which may be justified by the possible omission, since the frequency of patients who reported frequent alcohol consumption was only $9 \%$. This value is well below the national $(15 \%)^{19}$. For smoking, although there was also no statistically significant relationship with dysbiosis, the prevalence found was higher than the city average: $21,5 \%{ }^{20}$. This may be due to the higher prevalence of smokers in the hospital setting. Oliveira et al. ${ }^{21}$ found a prevalence of $17 \%$ of smokers among hospitalized patients, in a study carried out at the Hospital de Serviço Público Estadual de São Paulo (HSPE-SP), very close to that found in this study ${ }^{21}$.

For the item mobility, although there is no statistically significant relation with dysbiosis, it was verified that more than half of the patients in this condition $(n=7)$ have higher degrees of risk for dysbiosis. There was a low prevalence of bedridden patients (11\%), which may have hindered the statistical correlation.

The analysis of the relative frequencies of the dysbiosis degrees distribution showed a higher prevalence of medium and high dysbiosis risk: $43 \%$ and $39 \%$, respectively, distributed in a gaussian way and translating normal distribution. This data reflects the clinical profile of patients hospitalized at the Hospital de Clínicas da UFPR, showing the presence of several risk factors for dysbiosis. Thus, it establishes a warning about the need for future studies to verify intervention in the modifiable factors in order to reduce the additional morbidity generated by the condition of intestinal dysbiosis in hospitalized patients.

The National Dysbiosis Survey (INDIS) showed a useful tool to assess the risk factors of each patient and classification of dysbiosis risk. However, other validation studies are still lacking for its use as a diagnostic tool for dysbiosis. It is also worth noting the lack of "gold standard" methods for the dysbiosis diagnosis, which makes it difficult to validate instruments, such as, INDIS for diagnostic purposes. Recent studies have demonstrated efficacy in the use of genomic sequencing technologies for the dysbiosis diagnosis, but, besides being a high-cost method, there are still technical limitations for its clinical use ${ }^{22}$.

The research showed the importance of evaluating the risk factors for dysbiosis and the need to control those that are modifiable in order to reduce the morbidity of hospitalized patients. In addition, risk stratification alerts and makes it possible to select the subgroup of patients who may benefit from some intervention. Several authors have demonstrated benefits with the use of pre and probiotics prophylactically and therapeutically, with promising results, although this was not the objective of this study.

Further studies may determine the efficacy of this intervention in patients stratified as high risk of dysbiosis, as it is currently used empirically without evidence of the dysbiosis risks in each patient ${ }^{2,14,23}$. Finally, in view of the benefits of 
assessing the dysbiosis risk in a practical and simple way, such as the INDIS questionnaire, it is suggested to consider its use as an inpatient routine in order to allow the early identification of patients at high risk and very high risk for dysbiosis.

\section{REFERENCES}

1. Schippa S, Conte MP. Dysbiotic events in gut microbiota: impact on human health. Nutrients. 2014;6(12):5786-805.

2. Butel MJ, Waligora-DuprietAJ, Wydau-Dematteis S. The developing gut microbiota and its consequences for health. J Dev Orig Health Dis. 2018;9(6):590-7.

3. Ortega TT. Uso de perioperatório de probióticos em pacientes submetidos a ressecção de câncer colorretal: uma revisão sistemática. BRASPEN J. 2020;35(1):97-102.

4. Lankelma JM, Nieuwdorp M, de Vos WM, Wiersinga WJ. The gut microbiota in internal medicine: implications for health and disease. Neth J Med. 2015;73(2):61-8.

5. Almeida LB, Marinho CB, Souza CS, Cheib VBP. Disbiose intestinal. Rev Bras Nutr Clín. 2009;24(1):58-65.

6. Hawrelak JA, Myers SP. The causes of intestinal dysbiosis: a review. Altern Med Rev. 2004;9(2):180-97.

7. Noce A, Marrone G, Di Daniele F, Ottaviani E, Jones GW, Bernini $\mathrm{R}$, et al. Impact of gut microbiota composition on onset and progressing of chronic non-communicable diseases. Nutrients. 2019;11(5):1073.

8. Hirsch BE, Saraiya N, Poeth K, Schwartz RM, Epstein ME, Honig G. Effectiveness of fecal-derived microbiota transfer using orally administered capsules for recurrent Clostridium difficile infection. BMC Infect Dis. 2015;15(1):191.

9. Duda-Chodak A, Tarko T, Satora P, Sroka P. Interaction of dietary compounds, especially polyphenols, with the intestinal microbiota: a review. Eur J Nutr. 2015;54(3):325-41.

10. Lazar V, Ditu LM, Picalabioru GG, Picu A, Petcu L, Cucu N, et al. Gut microbiota, host organism, and diet trialogue in diabetes and obesity. Front Nutr. 2019;6:21.

11. Biagi E, Candela M, Fairweather-Tait S, Franceschi C, Brigidi P. Ageing of the human metaorganism: the microbial counterpart. Age. 2012;34(1):247-67.

12. Pérez-Cobas AE, Artacho A, Knecht H, Ferrús ML, Friedrichs A, Ott SJ, et al. Differential effects of antibiotic therapy on the structure and function of human gut microbiota. PLoS One. 2013;8(11):e80201.

13. Gorkiewicz G, Thallinger GG, Trajanoski S, Lackner S, Stocker G, Hinterleitner T, et al. Alterations in the colonic microbiota in response to osmotic diarrhea. PLoS One. 2013;8(2):e55817.

14. Hills Jr RD, Pontefract BA, Mishcon HR, Black CA, Sutton SC, Theberge CR. Gut microbiome: profound implications for diet and disease. Nutrients. 2019;11(7):1613.

15. Bengmark S. Gut microbiota, immune development and function. Pharmacol Res. 2013;69(1):87-113.

16. Ho JTK, Chan GCF, Li JCB. Systemic effects of gut microbiota and its relationship with disease and modulation. BMC Immunol. 2015;16(1):1-6.

17. Tojo R, Suarez A, Clemente MG, de los Reyes-Gavilán CG, Margolles A, Gueimonde M, et al. Intestinal microbiota in health and disease: role of bifidobacteria in gut homeostasis. World J Gastroenterol. 2014;20(41):15163-76.

18. Daian MR, Petroianu A, Alberti LR, Jeunon EE. Estresse em procedimentos cirúrgicos. ABCD. Arq Bras Cir Dig. 2012;25(2):118-24.

19. Laranjeira R, Pinsky I, Zaleski M, Caetano R. I levantamento nacional sobre os padrões de consumo de álcool na população brasileira. Brasília: Secretaria Nacional Antidrogas (SENAD); 2007. [cited 2020 May 2]. Disponível em: http:// bvsms.saude.gov.br/bvs/publicacoes/relatorio_padroes consumo_alcool.pdf

20. Brasil. Ministério da Saúde, Instituto Nacional do Câncer. Prevalência de tabagismo no Brasil: dados dos inquéritos epidemiológicos em capitais brasileiras. Rio de Janeiro: Ministério da Saúde, Instituto Nacional do Câncer; 2004. [cited 2020 May 2]. Disponível em: http://bvsms.saude.gov.br/bvs/publicacoes/ tabaco_inquerito_nacional_070504.pdf 21. Oliveira MVC, Oliveira TR, Pereira CAC, Bonfim AV, Leitão Filho FS, Voss LR. Tabagismo em pacientes internados em um hospital geral. J Bras Pneumol. 2008;34(11):936-41.

22. D'Argenio V, Salvatore F. The role of the gut microbiome in the healthy adult status. Clin Chim Acta. 2015;451(pt A):97-102.

23. LeBlanc AM, LeBlanc JG. Effect of probiotic administration on the intestinal microbiota, current knowledge and potential applications. World J Gastroenterol. 2014;20(44):16518-28.

Institution where the study was developed: Universidade Federal do Paraná, Curitiba, PR, Brazil.

Conflict of interest: The INDIS questionnaire was developed by FQM Farmoquímica. 


\section{APPENDIX}

\section{INDIS - NATIONAL DYSBIOSIS SURVEY - 2015}

Institution's name:

Patient's name:

Hospitalization unit:

No. of Medical Chart::

Bed:

Year:

Hospitalization date:

Procedure instructions: Complete the gaps below corresponding to the patient's assessment. The highlighted (green) questionnaire items are important risk factors for dysbiosis and when completed will correspond to the score indicated in the right column. Non-highlighted items (white) do not correspond to risk factors and, therefore, do not score. At the end of each item, there will be a subtotal the points of which should be summed up and placed in the risk stratification scale.

\section{PROFLE}

\begin{tabular}{|c|c|c|}
\hline \multicolumn{3}{|l|}{ Gender $r$} \\
\hline चMale & 口 Female & \\
\hline \multicolumn{3}{|c|}{ A ge range (THO classiffe ation): } \\
\hline Eiderly & $\square 60$ years o id and above & 1 point \\
\hline Adult & $\square 20$ to 59 yeass old & \\
\hline Adolescent & Dll to 19 yeas dd & \\
\hline Child & Do to 10 years oid & \\
\hline & $\begin{array}{c}\text { Score 1: } \\
\text { MAXIMUM SCORB: } 1 \text { PONT }\end{array}$ & Subtotal - \\
\hline
\end{tabular}

2.PATHOLOGIES AND/OR CLINICAL CONDITION

\begin{tabular}{|c|c|c|}
\hline Cardiology & 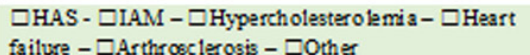 & \multirow{11}{*}{$\begin{aligned} & 1 \text { item }=1 \text { poirs; } \\
& 2 \text { items }=2 \text { poirts; } \\
& 3 \text { items }=3 \text { poirts; } \\
& 4 \propto \text { mare items }= \\
& 4 \text { points }\end{aligned}$} \\
\hline Endocine and metabolim & 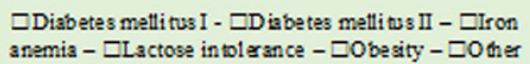 & \\
\hline Gastroenterology & 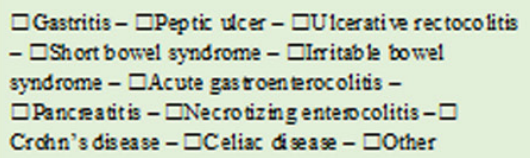 & \\
\hline Gynecology & $\begin{array}{l}\square \text { Endometriosis - } \square \text { Polycystic ovarian - } \square \text { Pregnant } \\
\text { - Other }\end{array}$ & \\
\hline $\begin{array}{l}\text { Hepatclogy } \\
\text { Immunology / A tlergy } \\
\text { Infectiology }\end{array}$ & 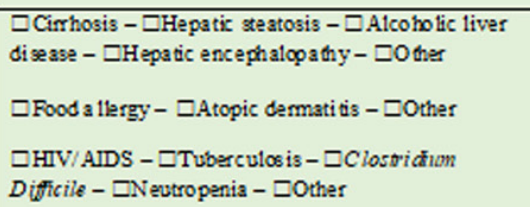 & \\
\hline Neusology / Psychiatric & 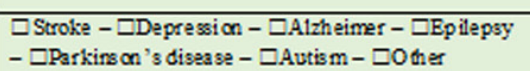 & \\
\hline Oncology & 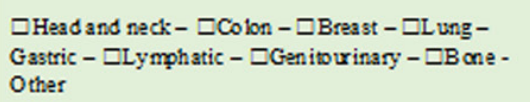 & \\
\hline Orthopedic / Rheumatology & 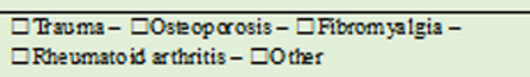 & \\
\hline Pneumology & 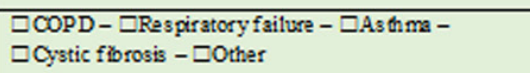 & \\
\hline Intensive therapy & 口Burn - ZMechanical ventilation - $\square$ Other & \\
\hline \multirow[t]{2}{*}{ No pathology } & Ex Check-up, etc. & \\
\hline & $\begin{array}{l}\text { Score } 2: \\
\text { M SCORB: } 4 \text { POINTS }\end{array}$ & Subtotal - \\
\hline
\end{tabular}




\begin{tabular}{|c|c|c|}
\hline \multicolumn{3}{|c|}{ 3. CURRENT TREA TMEN T } \\
\hline $\begin{array}{l}\text { \#Surgical - Which? } \\
\text { ¿Chemotherapy / Radiotherapy }\end{array}$ & $\begin{array}{l}\text { From } 7 \text { days before to } 7 \text { days after surgery } \\
\text { During treatment and } 1 \text { month afterwards }\end{array}$ & $\begin{array}{l}1 \text { point } \\
1 \text { point }\end{array}$ \\
\hline \multicolumn{3}{|l|}{ \#Clinical } \\
\hline \multicolumn{3}{|l|}{ Dother } \\
\hline & $\begin{array}{c}\text { Score 3: } \\
\text { MAX MUM SCORE: } 1 \text { PONNT }\end{array}$ & Subtotal - \\
\hline \multicolumn{3}{|c|}{ 4. GASTROINTE STINAL SYMPTOMS } \\
\hline $\begin{array}{l}\text { aDiarmea } \\
\text { EConstipation }\end{array}$ & $\begin{array}{l}\text { Minimum } 2 \text { days with liquid and lor pasty sto ols in the } \\
\text { past } 7 \text { days } \\
\text { Patient's complain + interviewercriterion }\end{array}$ & 5 points \\
\hline \multicolumn{2}{|l|}{ ニAbdominal pain } & \\
\hline \multicolumn{3}{|l|}{ DFlatulence - gases } \\
\hline \multicolumn{2}{|c|}{ MAXIMUM SCORB: 5 PONTS } & Subtotal \\
\hline \multicolumn{3}{|c|}{ 5. DRUGS } \\
\hline ¿Antibiotics - Which? & $\begin{array}{l}\text { Drring antibiotic therapy and for } 7 \text { days after } \\
\text { reatment }\end{array}$ & 4 points \\
\hline $\begin{array}{l}\text { DGastic shield - Which? } \\
\text { ¿L axative - Which? }\end{array}$ & $\begin{array}{l}\text { Dring treatment } \\
\text { During treatment (phamaceutical products: dngs, } \\
\text { fibers, herbal) }\end{array}$ & $\begin{array}{l}3 \text { points } \\
1 \text { point }\end{array}$ \\
\hline DAntidiarnheal - Which? & Drring treatment & 1 point \\
\hline \multicolumn{3}{|l|}{ Dother } \\
\hline & $\begin{array}{c}\text { SCORB 5: } \\
\text { MAXIMUM SCORB: 8 PONTS }\end{array}$ & Subtota1 - \\
\hline \multicolumn{3}{|c|}{ 6. SMOKING } \\
\hline ECurrent smoler & Smokes everyday & 1 point \\
\hline \multicolumn{3}{|l|}{ ZNon-smoler } \\
\hline & $\begin{array}{c}\text { SCORB 6: } \\
\text { MAXIMUM SCORB: } 1 \text { PONT }\end{array}$ & Subtotal - \\
\hline \multicolumn{3}{|c|}{ 7. ALCOHOL CONSUMPTION } \\
\hline ニConsumes often & From once a week & 1 point \\
\hline \multicolumn{3}{|l|}{ DConsumes eventually } \\
\hline \multicolumn{3}{|l|}{ DDoes not consume } \\
\hline & $\begin{array}{c}\text { SCORB 7: } \\
\text { MAXIMUM SCORB: } 1 \text { PONT }\end{array}$ & Subtota1 - \\
\hline \multicolumn{3}{|c|}{ 8. MOBILITY } \\
\hline aDoes not watk & $\begin{array}{l}\text { Restricted to bed } \propto \text { seduced mobility, but does not } \\
\text { walk }\end{array}$ & 1 point \\
\hline \multirow[t]{3}{*}{ ĐWalks } & Auxo-sufficient orreduced mobility, but walks & \\
\hline & $\begin{array}{l}\text { SCORB 8: } \\
\text { MAXMUM SCORB: } 1 \text { PONT }\end{array}$ & Subtota1 - \\
\hline & OVBRALL TOTAL: & \\
\hline
\end{tabular}

